Journal of Marine Systems

June 2016, Volume 158, Pages 129-139

http://dx.doi.org/10.1016/i.jmarsys.2016.02.003

http://archimer.ifremer.fr/doc/00317/42860/

(C) 2016 Elsevier B.V. All rights reserved.

\title{
Suppressing and enhancing effects of mesoscale dynamics on biological production in the Mozambique Channel
}

\author{
José Y.S. ${ }^{1,2, ~}{ }^{*}$, Penven P. ${ }^{2,3}$, Aumont O. ${ }^{4}$, Machu E ${ }^{3}$, Moloney C.L. ${ }^{5}$, Shillington F. ${ }^{2}$, Maury O. ${ }^{6,7}$ \\ ${ }^{1}$ Helmholtz Centre for Ocean Research Kiel, Germany \\ ${ }^{2}$ Department of Oceanography, Marine Research Institute (Ma-Re), University of Cape Town, South \\ Africa \\ ${ }^{3}$ Laboratoire de Physique des Océans (UMR 6523 CNRS, Ifremer, IRD, UBO), France \\ ${ }^{4}$ Laboratoire d'Océanographie et du Climat: Expérimentations et Approches Numériques (UMR 7159 \\ CNRS, UPMC, IRD, MNHN), France \\ ${ }^{5}$ Department of Biological Sciences, Marine Research Institute (Ma-Re), University of Cape Town, \\ South Africa \\ ${ }_{7}^{6}$ Institut de Recherche pour le Développement - UMR 248 MARBEC, , France \\ ${ }^{7}$ International Laboratory ICEMASA, Department of Oceanography, University of Cape Town, South \\ Africa
}

${ }^{*}$ Corresponding author : Y. S. José, email address : yjose@geomar.de

\begin{abstract}
:
We used a coupled physical-biogeochemical model to investigate how the strong eddy activity typical of the Mozambique Channel affects biological production. A numerical experiment was carried out, in which mesoscale dynamics were suppressed by cancelling the nonlinear terms for horizontal momentum in the Naviers-Stokes equation.

Mesoscale dynamics were found to be responsible for (1) increased offshore production in the Mozambique Channel as a result of net eddy-induced offshore transport of nutrient-rich coastal waters; (2) decreased shelf production along the central Mozambican and south-west Madagascar coast caused by a reduction in nutrient availability related to the net eddy-induced lateral transport of nutrients; (3) increased coastal production along the northern Mozambican coast caused by eddyinduced nutrient supply.

The model results also showed an intensification and shallowing of the subsurface production, related to increased upper layer nutrient concentrations caused by eddy activity.

In addition, by driving the detachment of the East Madagascar Current at the southern tip of the island, inertial processes intensify the southern Madagascar upwelling and causes offshore diffusion of the upwelled waters.
\end{abstract}

These results emphasize the complex role played by eddy activity and, more generally, inertial processes on marine ecosystems in this region. 
Keywords : Mesoscale dynamics, Chlorophyll, Primary production, Mozambique Channel

\section{Introduction}

By supplying nutrient-rich waters to the near surface layer which is depleted in nutrients, mesoscale eddies are known to play a key role in the stimulation of biological production (McGillicuddy et al., 1998; Oschlies and Gar, ${ }_{3}$ con, 1998; Williams and Follows, 1998; L'evy et al., 2001). This nutrient supply is primarily exercised through vertical pumping from subsurface nutrient-rich layers (McGillicuddy et al., 1998; Oschlies and Gar, ${ }_{3}$ con, 1998; L'evy et al., 2001) and lateral transport from nutrient-rich waters to low nutrient environments (Williams and Follows, 1998). This conventional view of eddies stimulating biological production was recently found inadequate in eastern boundary upwelling systems (Lathuiliere et al., 2010; Gruber et al., 2011). Using both observational and model simulated dynamics, Gruber et al. (2011) showed that eddy activity exerts a suppressive effect on coastal biological production in coastal upwelling systems. This reduction in coastal production was related to the eddy-induced intensification of lateral transport of coastal productive waters toward offshore regions (Gruber et al., 2011). This came in support of a study by Lathuilière et al. (2010), in which using an idealized circulation model of a coastal upwelling, the authors found a reduction of coastal production due to mesoscale variability. This finding raises the question of whether a reducing effect of eddy stirring on coastal production could also occur in regions 
with much stronger eddy activity. The present study aims to investigate the impact of mesoscale eddies on biological production in the Mozambique Channel, a region characterized by intense eddy activity, with a particular focus on the effect of eddy dynamics on coastal production.

The Mozambique Channel is a western boundary current system, where the eddy activity is among the strongest in the world (Chelton et al., 2007). The ocean circulation of the Mozambique Channel is dominated by large anticyclonic rings, which propagate southward through the Channel (Saetre and Silva, 1984; Grundlingh, 1995; de Ruijter et al., 2002; Schouten et al., 2003; Halo et al., 2014). These eddies are often in strong interaction with the continental shelf and the coastal regions (de Ruijter et al., 2002; Ternon et al., 2014; José et al., 2014). These eddy-shelf interactions result in offshore entrainment of coastal productive waters (Quartly and Srokosz, 2003; José et al., 2014; LebourgesDhaussy et al., 2014).

In this study, we used a coupled physical-biogeochemical model developed by José et al. (2014) to simulate realistically the dynamics of the Mozambique Channel. After validating the simulated dynamics against the observed data, we ran an idealized experiment in which we removed the terms responsible for the occurence of eddies. This was performed by canceling the advection of 40 momentum, all the other terms and parameters being kept strictly the same.

Gruber et al. (2011) have used the same method for testing the role of eddies on biological production in the California Current System. As described by Gruber et al. (2011), the advantage of this method over the coarsening of the horizontal resolution is a better preservation of large scale Ekman and geostrophic circulations. By using the method in which the advection of momentum are cancelled, we investigate the effects of mesoscale dynamics on biological production without including other potential sources of differences.

By comparing the realistic simulation with the idealized experiment, we demonstrate that the role of eddy activity on coastal production is complex, with both reducing and increasing coastal production, depending on the location. 


\section{Material and methods}

The physical-biogeochemical model configuration used for the Mozambique Channel consists of a hydrodynamic model ROMS (Regional Ocean Modelling System) coupled with a biogeochemical model PISCES (Pelagic Interaction Scheme for Carbon and Ecosystem Studies). This configuration is based on the ROMS_AGRIF two-way embedding procedure (Debreu et al., 2008, 2012) to nest a high resolution regional domain (child grid) within a larger scale domain (parent grid). ROMS is a split-explicit, free surface, terrain-following vertical coordinates ocean model, which solves the primitive equations of Navier Stokes in the presence of rotation (Shchepetkin and McWilliams, 2005). PISCES is a biogeochemical model that simulates the first trophic levels of the marine ecosystem and the biogeochemical cycles of carbon and the main nutrients (Aumont and Bopp, 2006). The PISCES parameterizations are described in detail in Aumont and Bopp (2006). This model has 24 compartments, of which four are living pools composed of two phytoplankton size-classes (nanophytoplankton and diatoms) and two zooplankton size-classes (microzooplankton and mesozooplankton). It incorporates phytoplankton growth limitation by five external nutrients: nitrate, ammonium, phosphate, silicate and iron. The Mozambique Channel configuration, described in detail by José et al. (2014), consists of a parent domain at $\frac{1}{2}^{\circ}$ horizontal resolution, covering the south-western Indian ocean, while the child grid domain at $\frac{1}{6}^{\circ}$ resolution extends from $32^{\circ} \mathrm{S}$ to $1.5^{\circ} \mathrm{S}$ and from $28^{\circ} \mathrm{E}$ to $61^{\circ} \mathrm{E}$. In this region characterized by a first baroclinic Rossby radius of deformation ranging from 50 to $100 \mathrm{~km}$ (Chelton et al., 1998), a resolution of $\frac{1}{6}^{\circ}$ resolves most of the spectrum of mesoscale eddies. This is confirmed by the level of mean eddy kinetic energy in Figure 1. The surface forcing fields consist of monthly climatologies presented by Penven et al. (2008) and atmospheric dust deposition from Fung and Tegen (1995). Due to the absence of reliable data on river nutrient discharges in this region, river inputs are not included in this configuration. Initial and boundary conditions for all the prognostic variables are derived from a monthly climatol- 
ogy of a NEMO/PISCES model simulation of the Indian Ocean (Koné et al., 2009). This realistic ROMS configuration is used as a reference and is referred to as $R E F$.

To quantify the impact of mesoscale dynamics on biological production, we have performed an experiment in which the mesoscale dynamics were suppressed $(N o A D V)$. To do so, we have cancelled the nonlinear advection terms in the Navier - Stokes equations for horizontal momentum. The cancellation of advection of momentum can be seen as a linearization for a low Rossby number, if we suppose that the eddies have neglectable upscaling effects on the large scale circulation. The absence of advection of momentum prevents the occurrence of coherent structures such as eddies and non linear cascades of energy (Yeung and Brasseur, 1991; Zhou, 1993; Eyink and Sreenivasan, 2006). This method is similar to the one described by Gruber et al. (2011) for their "non-eddy" simulation.

With the cancellation of these terms, we expect a suppression of eddies in the NoADV simulation, while the mean large scale circulation should be mostly preserved (since it follows linear Sverdrup dynamics).

Both simulations were run for a period of twenty climatological years, in which the model showed stable conditions after six years of simulation. Thus, the model outputs analyzed in this study were built by averaging, over the last ten years, the simulated fields of the high resolution child grid.

An extensive model - data comparison has been conducted using in situ climatologies and satellite products (José, 2014; José et al., 2014). It shows that the model is able to reproduce the mean state, seasonal cycle and eddy variability for physical and biogeochemical variables in the Mozambique Channel. 


\section{Results}

\subsection{Ocean circulation in the Mozambique Channel}

These results emphasize the underestimation of the magnitude of the surface currents by AVISO altimetry products (Ternon et al., 2014). By comparing 
AVISO and the in situ measured surface circulation, Ternon et al. (2014) found an underestimation of about $30 \%$ in altimetry observations compared to $A D C P$ tip of Madagascar by the detachment of the $E M C$ from the coast (Grundlingh et al., 1991). The NoADV experiment also highlights the role 
of south Madagascar dipole eddies (de Ruijter et al., 2004) on the northward intrusion of water from the south into the Mozambique Channel. REF and AVISO show a cyclonic loop in the south east part of the Channel which is not represented in $N o A D V$, where the flow is dominantly westward towards the African coast. This cyclonic loop could be related to a rectification effect due to the presence of cyclonic eddies generated south of Madagascar.

The suppression of mesoscale dynamics in NoADV reveals significant alterations in the current intensity and structure of the Mozambique Channel circulation related to eddy activity (Fig. 1-g,h). North of Madagascar, the $N M C$ appears intensified and confined inshore in NoADV (Fig. 1-h). Conversely, the following westward flow toward the African coast appears weaker in this simulation. In $R E F$, the core of the $N M C$ appears slightly detached from the shelf in the northern tip of Madagascar, allowing the generation of an eastward circulation inshore (around $12^{\circ} \mathrm{S}$ and $49^{\circ} \mathrm{E}$, Fig. 1-g, Fig. 2-a,b). This inshore eastward circulation has been related to the friction on the inshore edge of the $N M C$, which generates anticyclonic eddies that propagate into the Mozambique Channel (Backeberg and Reason, 2010). Reaching the northern Mozambique Channel, the anticyclonic eddies intensify and structure the flow through the Channel, with a southward flow along the western part and a northward flow along the eastern part of the Channel (Fig. 1-g,h and 2-c,d). This anticyclonic mean recirculation characteristic of the northern part of the Mozambique Channel is simulated in REF (Fig. 1-g) but is not present in NoADV (Fig. 1-h). This supports the findings of Collins et al. (2014), who related this recirculation to Mozambique Channel eddies. At the narrowest section of the Channel, around $17^{\circ} \mathrm{S}$, the southward flow along the African coast is extended offshore and is surface intensified in REF (Fig. 2-e,f), in agreement with in situ observed patterns (Ullgren et al., 2012). At the eastern Madagascar coast, the removal of mesoscale dynamics in $N o A D V$ did not affect the $E M C$ (Fig. 1-g,h). Downstream, at the southern tip of the island, the $E M C$ appears attached to the coast, intensifying the coastal current (Fig. 1-g,h and Fig. 2-g,h). In contrast to NoADV, the detachment of the EMC from the shelf break in the REF allows 
an eastward flow onshore (Fig. 2-g,h), triggering the formation of dipole eddies south of Madagascar (Fig. 2-g, h, de Ruijter et al. (2004); Siedler et al. (2009)).

The impact of eddy activity in the Mozambique Channel is also evident from surface temperature and salinity (Fig. 3). In the northern part of the Mozambique Channel, the surface waters are slightly colder and fresher in NoADV (Fig. 3-b,e). These changes seem to be related to the absence of the anticyclonic recirculation in $N o A D V$. With the anticyclonic recirculation in $R E F$, warmer waters on the central and northeastern side of the Mozambique Channel are diffused through the northern basin by the northward current present in the eastern Channel, increasing surface temperature (Fig. 3-a-c). A similar pattern is observed for salinity (Fig. 3-d-f). Similarly, saltier waters from the south are transported northward by the equatorward jet of the anticyclonic recirculation and are mixed with fresher surface water from the north-east, increasing salinity. Futher south inside the Channel, the warm and fresh Tropical Surface Water $(T S W)$, which propagates southward as a western boundary current, is closer to the shelf in $N o A D V$. In this case, a sharp density front separates the warmer and fresher water along the western boundary from the colder and saltier water offshore. With the presence of Mozambique Channel eddies, water mass properties are mixed and the horizontal density gradient is reduced. This way, temperature is increased and salt content is reduced along the coast. Offshore, eddy turbulent diffusion induces an increase in temperature and a decrease in salinity. South of Madagascar, detachment of the EMC from the coast in $R E F$ transports the warmer and fresher $T S W$ offshore. In addition, the cyclonic loop observed along the west Channel in REF brings southward warm and fresher waters from the central Mozambique Channel. Changes in water density induce changes in the mixed layer depth $M L D$. In the northern Channel, the $M L D$ is deeper in the west basin in $R E F$. This suggests that heat and salt redistribution by the Mozambique Channel eddies deepen the $M L D$ in the west side of the basin. Further south, the $M L D$ is dominantly shallower in $R E F$ compared to NoADV. An exception is observed offshore, coinciding with the region of horizontal density gradient in 
NoADV. This suggest that the mixing induced by eddy activity in this region deepens the $M L D$.

\subsection{Plankton and nutrient dynamics}

The seasonal cycles of sea surface chlorophyll for both SeaWiFS remote sens-

ing observations and REF are presented in Figure 4. The simulated chlorophyll concentrations follow the variability of the observations. They show lower concentrations during austral summer (Fig. 4-a,c) and higher concentrations during austral winter (Fig. 4-b,d). This variability is related to seasonal changes in the upper layer nutrient availability driven by variations of the mixed layer (Machu et al., 2005). In austral winter, surface cooling generates a deeper mixing, bringing upward deep nutrient-rich waters, which stimulates plankton production. In the Somalian upwelling region (north of $\left.6^{\circ} \mathrm{S}\right)$, high chlorophyll concentrations are more extensive during austral winter. In the subtropical gyre (i.e. offshore of Madagascar), chlorophyll concentrations are low in the model, in line with SeaWiFS observations. Although the model is able to reproduce the seasonal variability of the chlorophyll concentration, it fails to reproduce the higher concentrations along the coast, as well as the phytoplankton plume which is noticeable south-east of Madagascar in austral summer (Longhurst, 2001). The weak production along the coast could be related to the absence of a sediment compartment as well as river nutrient discharges in the model simulation. Both resuspension from sediments as well as river discharges enrich the coastal waters with nutrients, enhancing coastal productivity (Lohrenz et al., 1997; Johnson et al., 1999; Booth et al., 2000). The seasonal phytoplankton plume south-east of Madagascar has been recently related to nitrogen fixers (Srokosz and Quartly, 2013), which are not explicitly accounted in for the phytoplankton formulation used in the model.

The effect of mesoscale dynamics on plankton production is summarized in the annual mean primary production presented in Figure 5. In NoADV, the productivity is more localized and confined to coastal regions of the 
Channel (Fig. 5-b). In the presence of eddies in $R E F$, coastal productive waters are diffused further offshore (Fig. 5-a). The differences in primary production calculated as REF - NoADV are positive along the north coast of Mozambique (between $16^{\circ} \mathrm{S}$ and $10^{\circ} \mathrm{S}$ ), the central west coast (between $21^{\circ} \mathrm{S}$ and $17^{\circ} \mathrm{S}$ ) and at the southern tip of Madagascar (Fig. 5-c). This is in contrast to reduced primary production in REF along the central Mozambican coast (between $25^{\circ} \mathrm{S}$ and $17^{\circ} \mathrm{S}$ ) and south west of Madagascar (between $26^{\circ} \mathrm{S}$ and $23^{\circ} \mathrm{S}$, Fig. 5-c). Offshore in the Mozambique Channel, patterns are more homogeneous with generally increased surface primary production in the simulation with eddies. The vertical structure of primary production shows deeper and weaker subsurface maxima in $N o A D V$ (Fig. 5-e). The shallower subsurface maxima in REF suggests an increase of upper layer nutrients induced by eddy dynamics (Fig. 5-d).

To interpret these patterns, we examined the changes in nitrate (Fig. 6- $a-c$ ), which has been suggested to be the limiting factor for phytoplankton production in the Mozambique Channel (Koné et al., 2009). In the northern Mozambique Channel (between 12-17 ${ }^{\circ} \mathrm{S}$ ), REF displays reduced surface nitrate concentrations compared to NoADV. This reduced surface nitrate concentration is in contrast to the patterns of productivity presented in Figure 5-c. Phytoplankton growth limitation by nitrate however, follows the production pattern (Fig. 6- $d-f$ ). It shows that phytoplankton cells are less limited by nitrate in the west side of the basin compared to the east side in REF (Fig. 6- $d$ ). The eddy-driven nitrate transport show a relation with the enhanced production in the west and reduced production in the east side of the basin (Fig. 7-a,b). It shows elevated nitrate supply from the north-western side of the basin in REF (Fig.7-a), coinciding with the Mozambique Channel eddies main pathway (Halo et al., 2014). In the east side, the eddy-driven nitrate transport is weak and mainly northward. This northward transport is linked to the anticyclonic eddy characteristic of the northern Channel (Collins et al., 2014), which brings less productive waters from the central Channel. In NoADV, there is a strong southward transport of ni- 
trate in the north-east side of the basin (Fig.7-b), which explains the enhanced plankton production in Figure 5-c.

Considering now the central Mozambique Channel, the reduction in coastal induced lateral as well as upward transport of nitrate-rich deep waters 
(Fig. 8- $d$ ) increases the upper layer nutrient concentrations and shoals the nutricline (Fig. 8- $a$ ). Thus, phytoplankton growth is enhanced offshore by eddy activity (Fig. $5-d-f$ ). The increase of upper layer nutrients and primary production, as well as the favorable light conditions, results in an intensification and shoaling of the subsurface production (Fig. 5- $d-f$ ). The auto-shading effect (reduction of deep penetration of light due to increased surface production) is also intensified. This can be seen from the vertical distribution of photosynthetically available radiation $(P A R$, Fig. $8-f-h)$. The $P A R$ is more attenuated in $R E F$ (Fig. 8- $f$ ) than in NoADV (Fig. 8- $g$ ) simulation. This auto-shading effect reduces phytoplankton production below the subsurface maximum (Fig. 5- $d-f$ ).

\section{Discussion}

The aim of this study is to understand the role of mesoscale dynamics on the phytoplankton production in the Mozambique Channel, known for its strong eddy activity. We approached this task by implementing an idealized experiment in which the processes responsible for small scale generation are removed from the momentum equations. Both mean patterns and turbulent fluxes of this experiment are compared to an eddy-resolving realistic simulation. The cancellation of the non-linear terms did not affect the mean large scale circulation outside the Mozambique Channel (Fig. 1- $g, h$ ). In the Channel, the mean circulation appear strongly modified by mesoscale 345 dynamics, emphasizing the strong role played by eddy activity on the flow of the Mozambique Channel (Grundlingh, 1995; de Ruijter et al., 2002; Schouten et al., 2003). To the north, the results suggest that the anticyclonic recirculation characteristic of this region (Collins et al., 2014) shape the circulation patterns, by inducing a northward flow on the east side of the basin. This northward flow allows a northward transport of warmer and saltier waters from the 
central Channel (Fig. 3). These waters are mixed with the relatively cooler and fresher TSW brought into the Channel by the SEC ( Schott and McCreary (2001)). Further south, the TSW are diffused offshore by the eddy stirring, reducing the northward propagation of cold southern waters. During this process, waters inshore got saltier and colder while waters offshore got fresher and warmer (Fig. 3). The changes in the circulation and water mass properties lead to changes in the phytoplankton productivity. It came into view that the eddies in the Mozambique Channel could induce both a reduction and an increase of coastal production (Fig. 5- $a, b$ ). The reduction of coastal production (which occurs in the central-west and south-east Mozambique Channel) is related to the eddy-induced off-shelf transport of coastal-productive waters, which reduces the coastal nutrient (Fig. 7$c, d)$. With limited nutrients, the phytoplankton growth is reduced due to nutrient-stress (Fig. 6-d,e), thus the productivity (Fig. 5-c). A similar relationship has been described by Gruber et al. (2011) and Lathuilière et al. (2010) in the eastern tropical upwelling systems. The increased coastal production (which occurs in the northern Channel, Fig. 5-a) is related to the eddy-induced nutrient injection into the $M L D$ (Fig. 7-a,b), as they intensify the southward flow through the Channel (Fig. 2- $c, d$ ). Vertically, the eddy-induced upward transport of nutrient-rich deep waters (Fig. 8- $d$ ) combined with eddy-induced lateral transport (Fig. 7- $a, c$ ) increases the upper layer nutrient concentration (Fig. 8-a). This is in agreement with the study by (Oschlies and Garçon, 1998), in which they found about one-third of the total flux of nitrate into the euphotic zone related to eddy activity.

\section{Conclusions}

It has been shown that eddy activity exerts a suppressive effect on coastal production in eastern boundary upwelling systems, by intensifying the lateral 
transport of nutrient-rich coastal waters (Lathuilière et al., 2010; Gruber et al., 2011). Gruber et al. (2011) have subsequently suggested that a similar effect might occur in other regions characterized by strong eddy activity. Our study on the Mozambique Channel, a region strongly dominated by eddy activity, showed heterogeneous and complex biological responses to eddy activity, with different processes involved in the induced changes. In this region, the mesoscale dynamics have both suppressive, as documented in eastern boundary systems by Gruber et al. (2011), and enhancing effects close to the shore. The suppressive effect was related to eddy-induced offshore transport of coastal nutrients combined with a reduction in nutrient injection from the lateral boundaries.

The enhancing effect was linked to the intensification of the southward transport of nutrient-rich waters throughtout the northern boundary of the Mozambique Channel. On this basis, it is evident that the role of small-scale dynamics in the marine ecosystem is complex. Their effects on bi-

ological production are diverse. This complexity is strongly dependent on the circulation patterns at regional scales, which override the applicability of general schemes. Furthermore, this study emphasizes the need for a good representation of regional circulation patterns in global scale physical models to better understand and predict future changes in ocean biogeochemical dynamics.

400

Aumont O, Bopp L. Globalizing results from Ocean in situ iron fertilization studies. Global Biogeochemical Cycles 2006;20:1-15. doi:10.1029/ 2005 GB002591.

Backeberg BC, Reason CJC. A connection between the South Equatorial Current north of Madagascar and Mozambique Channel Eddies. Geophysical Research Letters 2010;37:1-6. doi:10.1029/2009GL041950.

Booth JG, Miller RL, McKee BA, Leathers RA. Wind-induced bottom sediment resuspension in a microtidal coastal environment. Continental Shelf Research 2000;20:785-806. 
Chelton DB, deSzoeke RA, Schlax MG, Naggar KE, Siwertz N. Geographical variability of the first-baroclinic rossby radius of deformation. Journal of Physical Oceanography 1998;27:186-94.

Chelton DB, Schlax MG, Samelson RM, de Szoeke RA. Global observations of large oceanic eddies. Geophysical Research Letters 2007;34:1-5. doi:10. 1029/2007GL030812.

Collins C, Hermes JC, Reason CJC. Mesoscale activity in the Comoros Basin from satellite altimetry and a high-resolution ocean circulation model. Journal Geophysical Research 2014;119:4745-4760. doi:10.1002/2014JC010008.

de Ruijter WPM, Ridderinkhof H, Lutjeharms JRE. Observations of the flow 420 in the Mozambique Channel. Geophysical Research Letters 2002;29:141-3. doi:10.1029/95JC01985.

Debreu L, Marchesiello P, Penven P, Cambon G. Two-way nesting in splitexplicit ocean models: algorithms, implementation and validation. Ocean Modelling 2012;49-50:1-21. doi:10.1016/j .ocemod.2012.03.003.

Debreu L, Vouland C, Blayo E. AGRIF: Adaptive grid refinement in fortran. Computers Geosciences 2008;34:8-13. doi:10.1016/j.cageo.2007.01.009.

Eyink GL, Sreenivasan KR. Onsager and the theory of hydrodynamic turbulence. Rev Mod Phys 2006;78:87-135. doi:10.1103/RevModPhys.78.87.

Fung I, Tegen I. Contribution to the atmospheric mineral aerosol load from land surface modification. Journal Geophysical Research 1995;100:18707-18726. doi:10.1029/95JD02051.

Gruber N, Lachkar Z, Frenzel H, Marchesiello P, Munnich M, McWilliams LC, Nagai T, Plattner GK. Eddy-induced reduction of biological production in eastern boundary upwelling systems. Nature geoscience 2011;4:1-6. doi:10 . 1038/NGE01273. 
Grundlingh M, Carter R, Stanton R. Circulation and water properties of the southwest indian ocean, spring 1987. Progress in Oceanography 1991;28:30542.

Grundlingh ML. Tracking eddies in the southeast Atlantic and southwest Indian oceans with TOPEX/POSEIDON. Journal Geophysical Research 1995;100:24977-86. doi:10.1029/95JC01985.

Halo I, Backeberg B, Penven P, Reason C, Ansorge I, Ulgren J. Eddy properties in the Mozambique Channel: A comparison between satellite altimetry and Ocean Circulation models. Deep Sea Research II 2014;100:119-35. doi:10 . $1016 / j \cdot d s r 2.2013 \cdot 10 \cdot 015$.

Johnson KS, Chavez FP, Friederich GE. Continental-shelf sediment as a primary source of iron for coastal phytoplankton. Letters to nature 1999;398:697-700.

José YS. Mesoscale structuring of the pelagic ecosystem in the mozambique channel: a modelling approach. Univ of cape Town 2014;.

José YS, Aumont O, Machu E, Penven P, Moloney CL, Maury O. Influence of mesoscale eddies on biological production in the Mozambique Channel: Several contrasted examples from a coupled ocean-biogeochemistry Model. Deep Sea Research II 2014;100:79-93. doi:10.1016/j.dsr2.2013.10.018.

Koné V, Aumont O, Lévy M, Resplandy L. Physical and biogeochemical controls of the phytoplankton seasonal cycle in the Indian Ocean: A Modelling Study. Geophysical Monograph Series 2009;23:147-66. doi:10.1029/2008GM000700.

Lathuilière C, Echevin V, Lévy M, Madec G. On the role of the mesoscale circulation on an idealized coastal upwelling ecosystem. Journal of Geophysical Research 2010;115:1-14. doi:10.1029/2009JC005827.

Lebourges-Dhaussy A, Huggett J, Ockhuis S, Roudaut G, Josse E, Verheye H. Zooplankton size and distribution within mesoscale structures in the Mozambique Channel: a comparative approach using the TAPS acoustic profiler, 
a multiple net sampler and ZooScan image analysis. Deep Sea Research II 2014;100:136-52. doi:10.1016/j.dsr2 .2013.10.022.

Lévy M, Klein P, Treguier AM. Impact of sub-mesoscale physics on production and subduction of phytoplankton in an oligotrophic regime. Journal of Marine Research 2001;59:535-65.

Lohrenz SE, Fahnenstiel GL, Redalje DG, Lang GA, Chen X, Dagg MJ. Variations in primary production of northern gulf of mexico continental shelf waters linked to nutrient inputs from the mississipi river. Marine Ecology Progress Series 1997;155:45-54.

Longhurst A. A major seasonal phytoplankton bloom in the Madagascar Basin. Deep Sea Research I 2001;48:2413-22. doi:10.1016/S0967-0637(01) 00024-3.

Machu E, Biastoch A, Oschlies A, Kawamiya M, Lutjeharms J, Garçon V. Phytoplankton distribution in the Agulhas system from a coupled physicalbiological model. Deep Sea Research I 2005;52:1300-18. doi:10.1016/j .dsr . 2004.12 .008$.

Machu E, Lutjeharms JRE, Webb AM, van Aken HM. First hydrographic evidence of the southeast Madagascar upwelling cell. Journal Geophysical Research 2002;29:1-5. doi:10.1029/2002GL015381.

McGillicuddy D, Robinson AR, Siegel DA, Jannasch HW, Johnson R, Dickey TD, McNeil J, Michaels AF, Knap AH. Influence of mesoscale eddies on new production in the Sargasso Sea. Nature 1998;394:263-6.

New A, Magalhaes J, da Silva J. Internal solitary waves on the saya de malha bank of the mascarene plateau: Sar observations and interpretration. Deep Sea Research Part I 2013;79:50-61. doi:doi:10.1016/j.dsr.2013.05.008.

Oschlies A, Garçon V. Eddy-induced enhancement of primary production in a model of the North Atlantic Ocean. Nature 1998;394:266-9. doi:10.1038/ 28373. 
Palastanga V, van Leeuwen PJ, de Ruijter WPM. A link between lowfrequency mesoscale eddy variability around Madagascar and the largescale Indian Ocean variability. Journal Geophysical Research 2006;111:1-15. doi:10.1029/2005JC003081.

Palastanga V, van Leeuwen PJ, Schouten MW, de Ruijter WPM. Flow structure and variability in the Subtropical Indian Ocean: Instability of the South Indian Ocean Countercurrent. Progress in Oceanography 2007;112:1-11. doi:10.1029/2005JC003395.

Penven P, Marchesiello P, Debreu L, Lefevre L. Software tools for pre- and post-processing of oceanic regional simulations. Environmental Modelling and Software 2008;23:660-2. doi:10.1016/j . envsoft.2007.07.004.

Quartly GD, Srokosz MA. A plankton guide to ocean physics: Colouring in the Currents around South Africa and Madagascar. The Challenger Society for Marine Science 2003;12:19-21.

de Ruijter WPM, van Aken HM, Beier EJ, Lutjeharms JR, Matano RP, Schouten MW. Eddies and dipoles around South Madagascar: formation, pathways and large-scale impact. Deep Sea Research Part I 2004;51:383-400. doi:10.1016/j.dsr.2003.10.011.

Sá C, Leal MC, Silva A, Nordez S, Andr/'e E, Paula J, Brotas V. Variation of phytoplankton assemblages along the mozambique coast as revealed by hplc and microscopy. Journal of Sea Research 2013;79:1-11. doi:10.1016/j. seares.2013.01.001.

Saetre R. Surface currents in the Mozambique Channel. Deep Sea Research $1985 ; 32: 1457-67$.

Saetre R, Silva AJD. The circulation of the Mozambique Channel. Deep Sea Research Part A Oceanographic Research Papers 1984;31:485-508. doi:10. 1016/0198-0149(84)90098-0. 
Schott AM, Dengler M, Schoenefeldt R. The shallow overturning circulation of the Indian Ocean. Progress in Oceanography 2002;53:57-103. doi:10.1016/ S0079-6611(02)00039-3.

Schott AM, McCreary JP. The monsoon circulation of the Indian Ocean. Progress in Oceanography 2001;51:1-123. doi:10.1016/S0079-6611(01) 00083-0.

Schouten MW, de Ruijter APM, van Leeuwen PJ, Ridderinkhof H. Eddies and variability in the Mozambique Channel. Deep Sea Research Part II: Topical Studies in Oceanography 2003;50:1987-2003. doi:10.1016/S0967-0645(03) 00042-0.

Shchepetkin AF, McWilliams JC. The regional oceanic modeling system (ROMS): a split-explicit, free-surface, topography-following-coordinate oceanic model. Ocean Modelling 2005;9:347-404. doi:10.1016/j.ocemod. 2004.08 .002 .

Siedler G, Rouault M, Biastoch A, Backeberg B, Reason CJC, Lutjeharms JRE. Modes of the southern extension of the East Madagascar Current. Journal Geophysical Research 2009;114:1-15. doi:10.1029/2008JC004921.

Srokosz MA, Quartly GD. The Madagascar Bloom: A serendipitous study. Journal Geophysical Research 2013;118:14-25. doi:10.1029/2012JC008339.

Ternon JF, Roberts M, Morris T, Hancke L, Backeberg B. Eddies and variability in the Mozambique Channel. Deep Sea Research II 2014;100:10-26. doi:10 . $1016 / j \cdot d s r 2.2013 \cdot 10 \cdot 013$.

Ullgren JE, van Aken HM, Ridderinkhof H, de Ruijter WPM. The hydrography of the Mozambique Channel from six years of continuous temperature, salinity, and velocity observations. Deep Sea Research I 2012;69:36-50. doi:10.1016/j.dsr.2012.07.003.

Williams RG, Follows MJ. The Ekman transfer of nutrients and maintenance of new production over the North Atlantic. Deep Sea Research I 1998;45:461-89. 
Yeung PK, Brasseur JG. The response of isotropic turbulence to isotropic and anisotropic forcing at the large scales. Phys Fhuids 1991;A3:884-97. doi:10. 1063/1.857966.

Zhou Y. Interacting scales and energy transfer in isotropic turbulence. Phys 

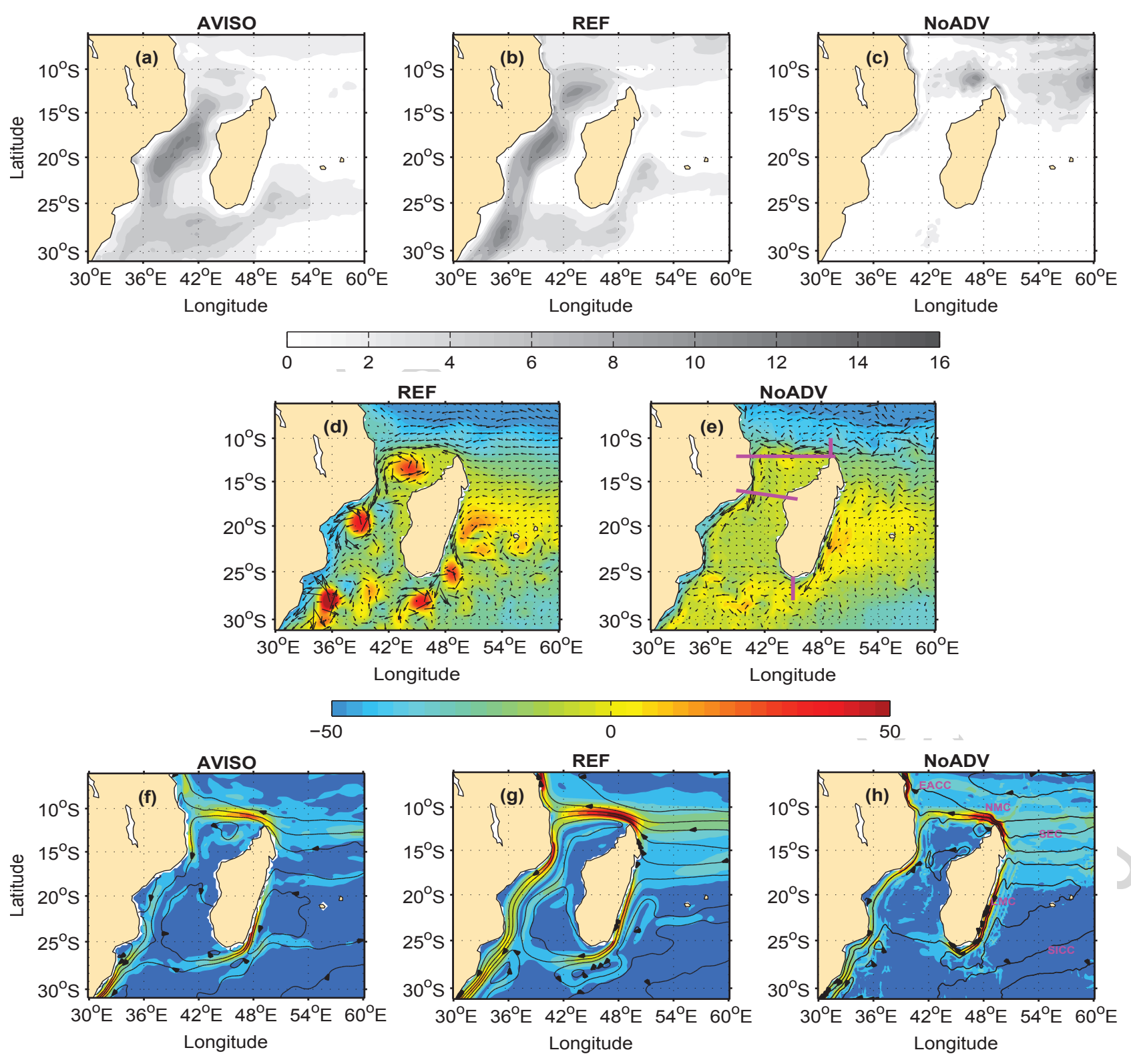

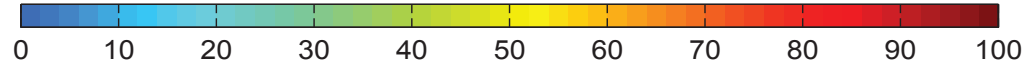

Figure 1: Sea surface physical dynamics of the south western Indian ocean. (a-c) eddy kinetic energy $\left[10^{2} \times \mathrm{cm}^{2} \mathrm{~s}^{-2}\right]$, $(\mathrm{d}, \mathrm{e}) \mathrm{sea}$ surface currents (arrows) overlaid on sea surface anomaly [cm] for early December of model year 20 and (f-h) sea surface height [contour every $10 \mathrm{~cm}]$ overlayed on the current intensity [cm.s ${ }^{-1}$ ]. Variables corresponding to $A V I S O$ observations (a,f), REF simulation (b,d,g) and NoADV experiment (c,e,h). Magenta lines in panel (e) show the location of the vertical sections displayed on Fig. 2. 

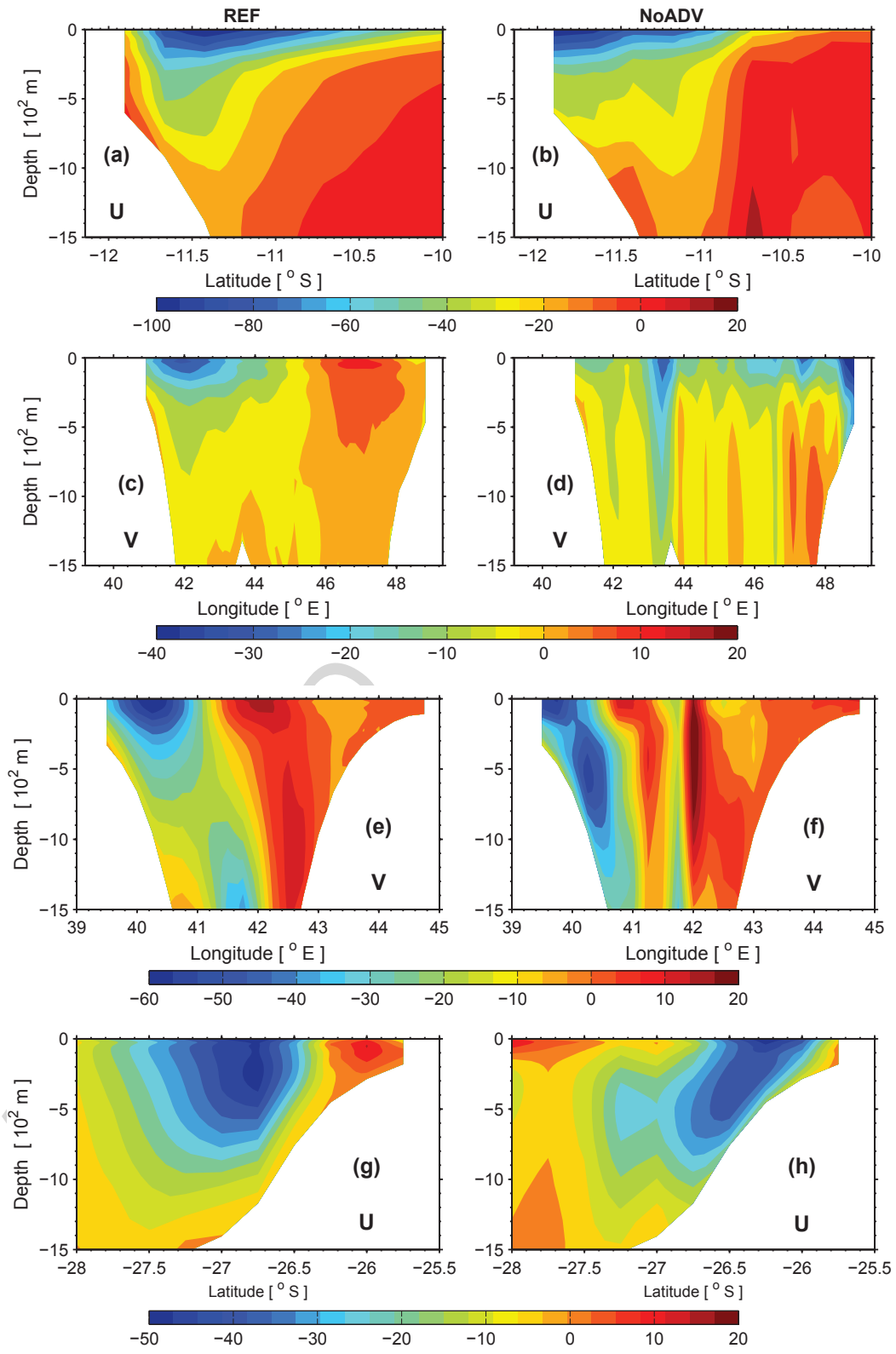

Figure 2: Vertical structure of the mean velocity $\left[\mathrm{cm} \cdot \mathrm{s}^{-1}\right] .(\mathrm{a}, \mathrm{b})$ Zonal velocity $(\mathrm{U})$ at the northern tip of Madagascar, around $49^{\circ} \mathrm{E}$. (c,d) Meridional velocity (V) at the northern border of the Mozambique Channel, around $12^{\circ} \mathrm{S}$. (e,f) Meridional velocity (V) at the narrowest part of the Mozambique Channel, around $17^{\circ} \mathrm{S}$. $(\mathrm{g}, \mathrm{h})$ Zonal velocity (U) at the southern tip of Madagascar, $45^{\circ} \mathrm{E}$. Model results corresponding to REF (left panels) and NoADV (right panels). The locations of the sections are presented on Fig. 1-e. 

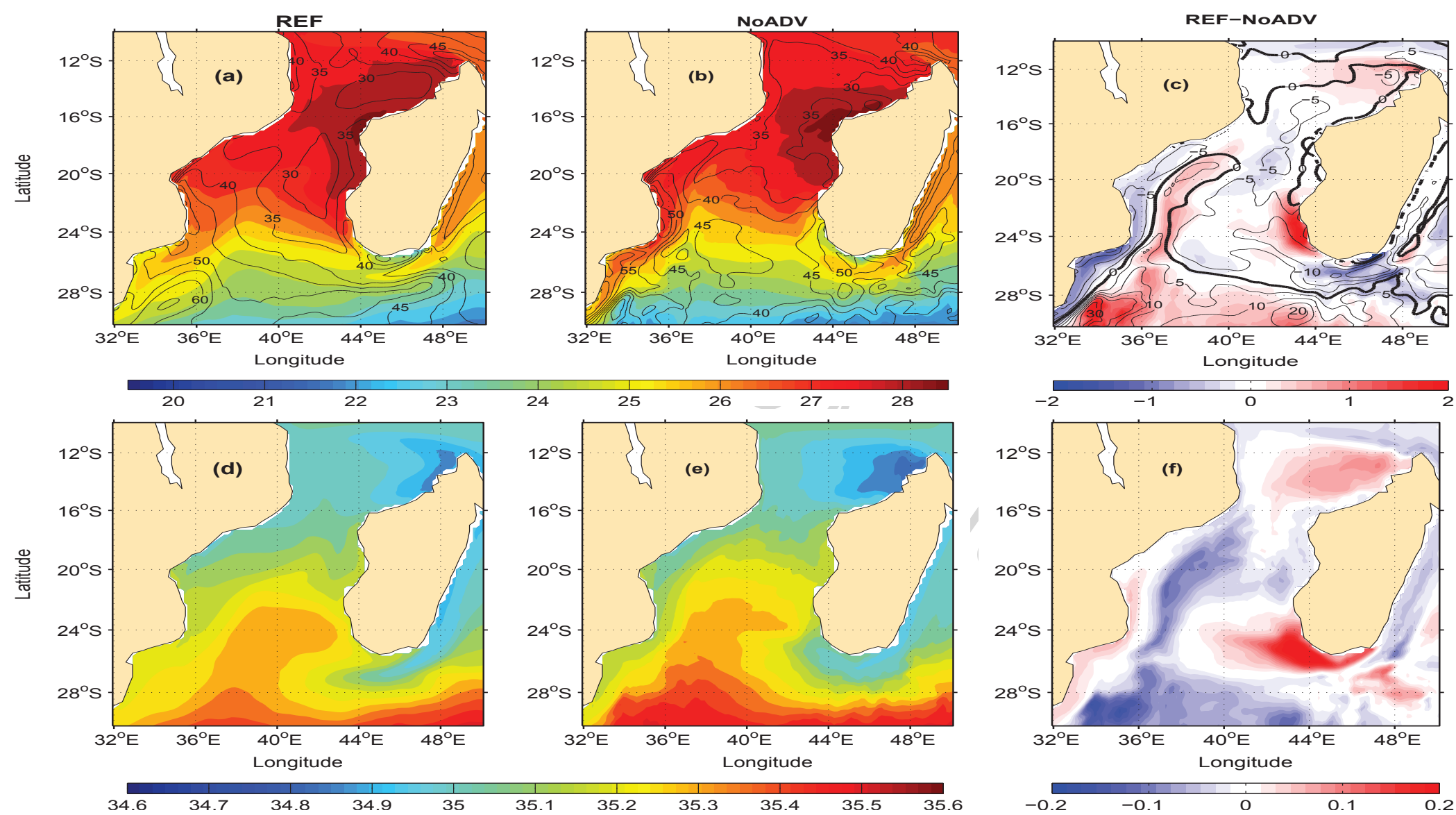

Figure 3: Mean mixed layer depth $[\mathrm{m}]$ overlaid on mean sea surface temperature $\left(\left[^{\circ}\right]\right.$, a-c) and mean salinity (d-f), corresponding to $R E F$ (left panels), NoADV (middle column) and the REF-NoADV anomalies (right panels). 

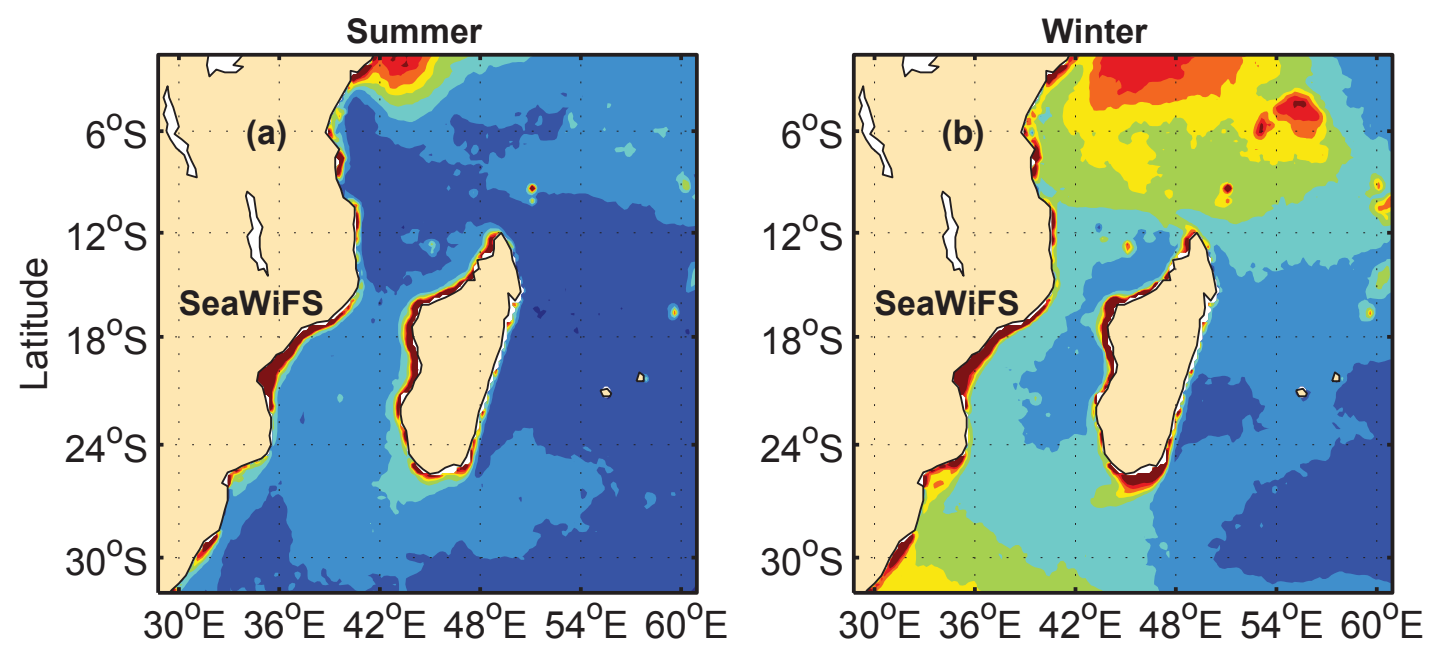

N
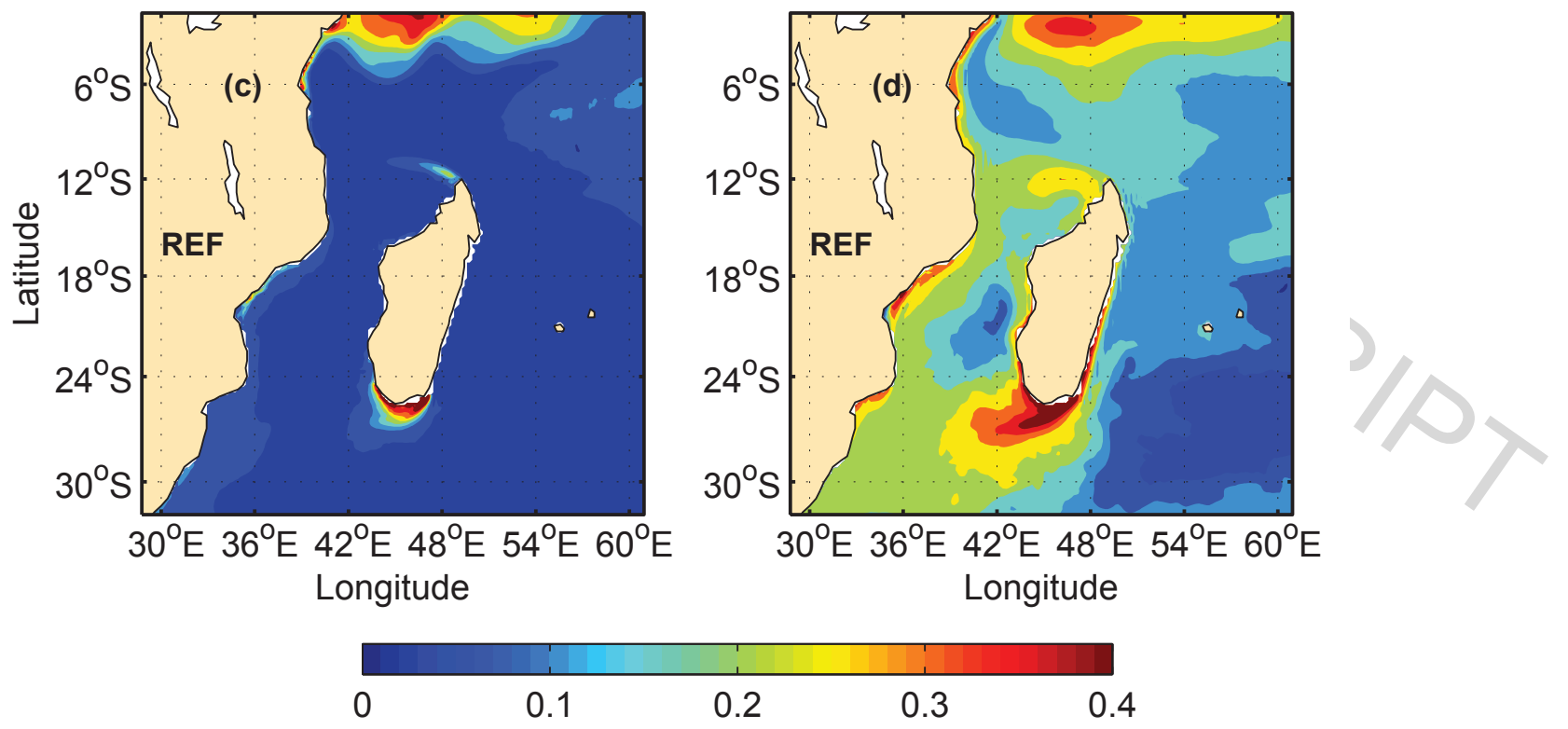

Figure 4: Seasonal variability of sea surface chlorophyll $\left[\mathrm{mg} \cdot \mathrm{m}^{-3}\right]$, corresponding to SeaWiFS observations (a,b) and $R E F$ simulation (c,d). The high production occurs in austral winter season (right panels) in both observed and simulated phytoplankton distributions. 
REF

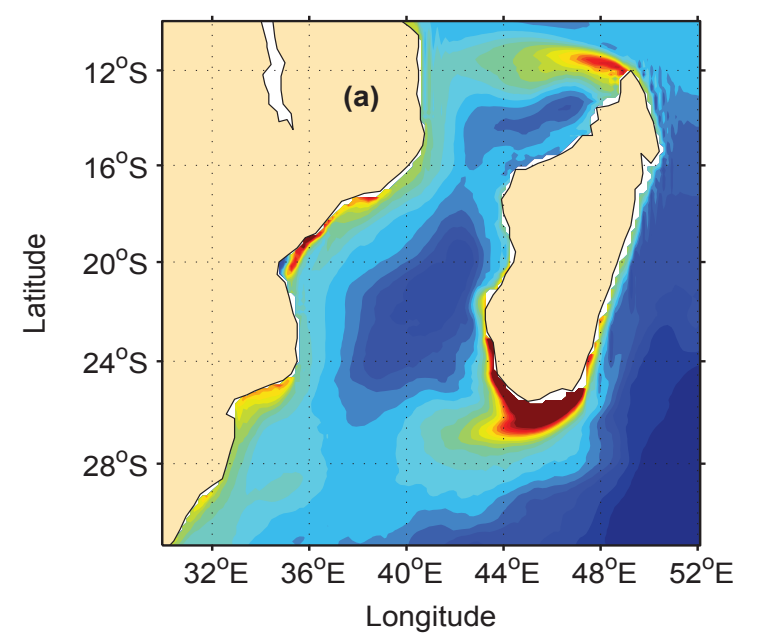

NoADV

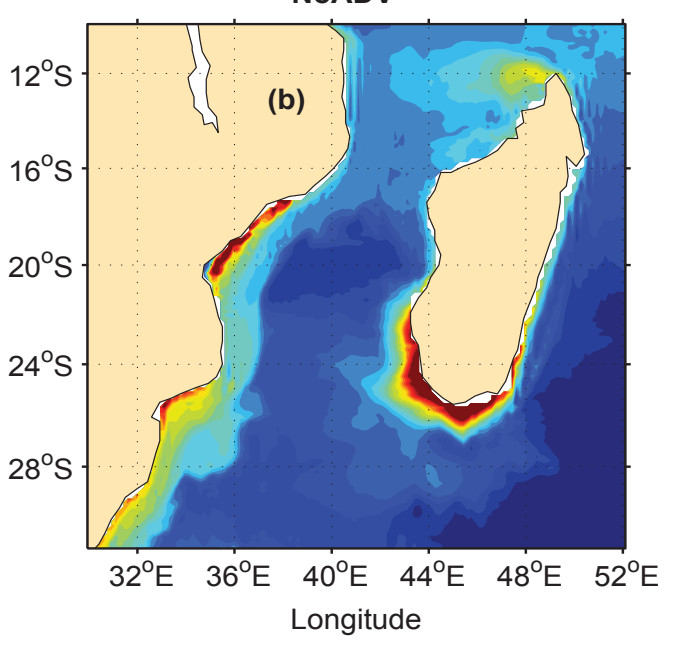

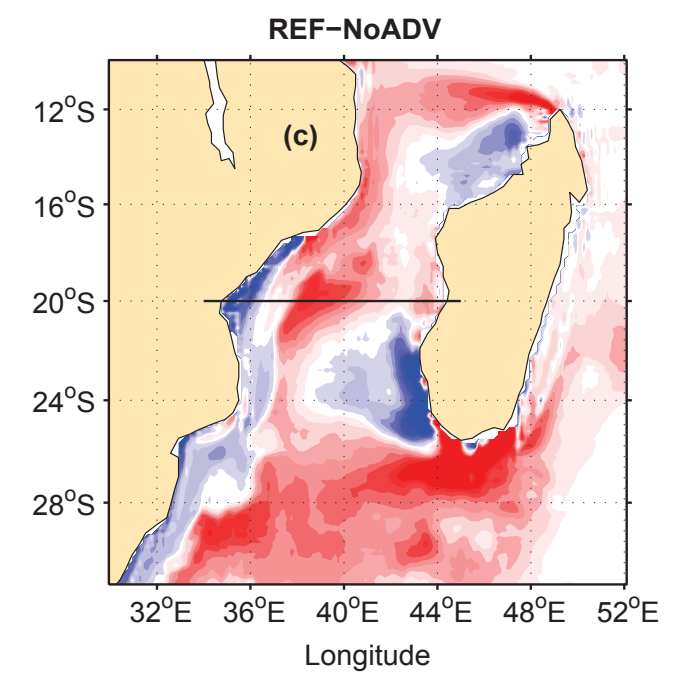
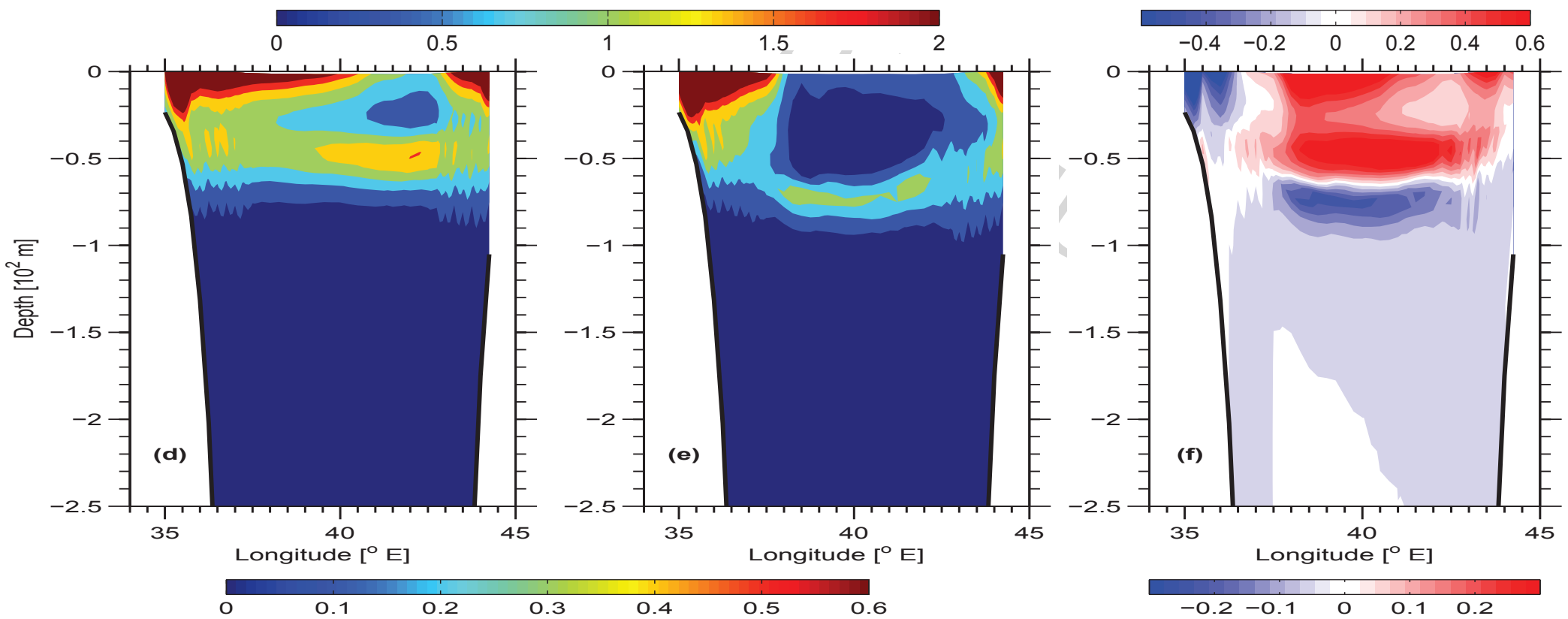

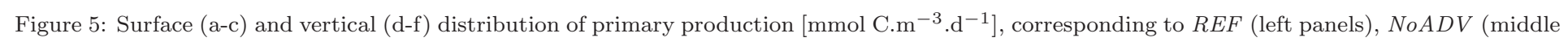
column) and the REF-NoADV anomalies (right panels). The black line in panel (c) shows the location of the section shown on Figure 8 and panels d,f. 

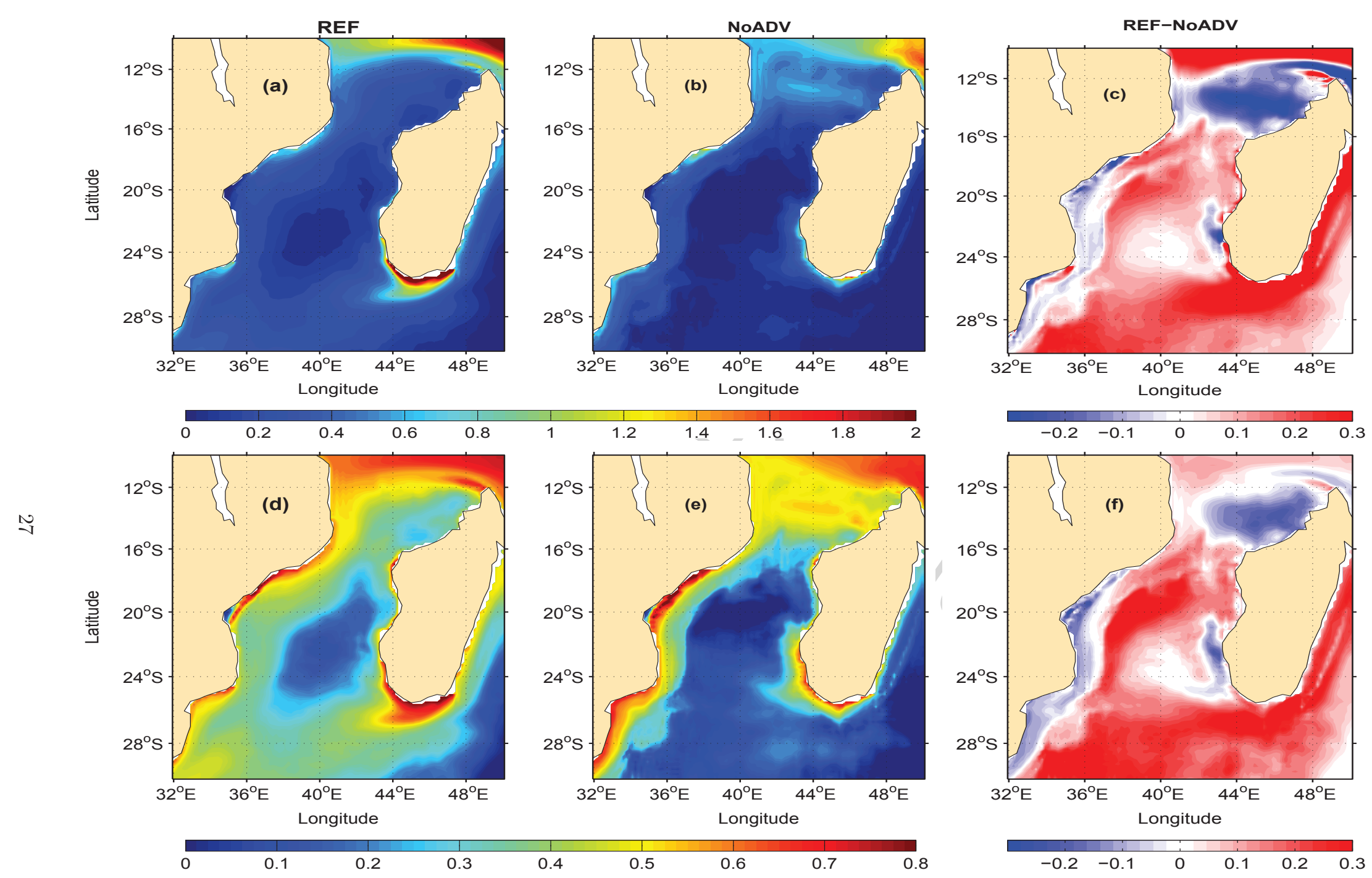

Figure 6: (a-c) Surface distribution of nitrate $\left[\mu \mathrm{mol} . \mathrm{L}^{-1}\right]$ in the upper $50 \mathrm{~m}$ depth, corresponding to the $R E F$ simulation and the $R E F$ - NoADV anomaly. (d-f) The same as (a-c), but for Surface distribution of nanophytoplankton growth limitation by nitrate. Phytoplankton is limited by nitrate when values are below 0.5. For the limitation, we focus our analysis on nanophytoplankton because they represent the most abundant plankton community in this region (Sá et al., 2013). 

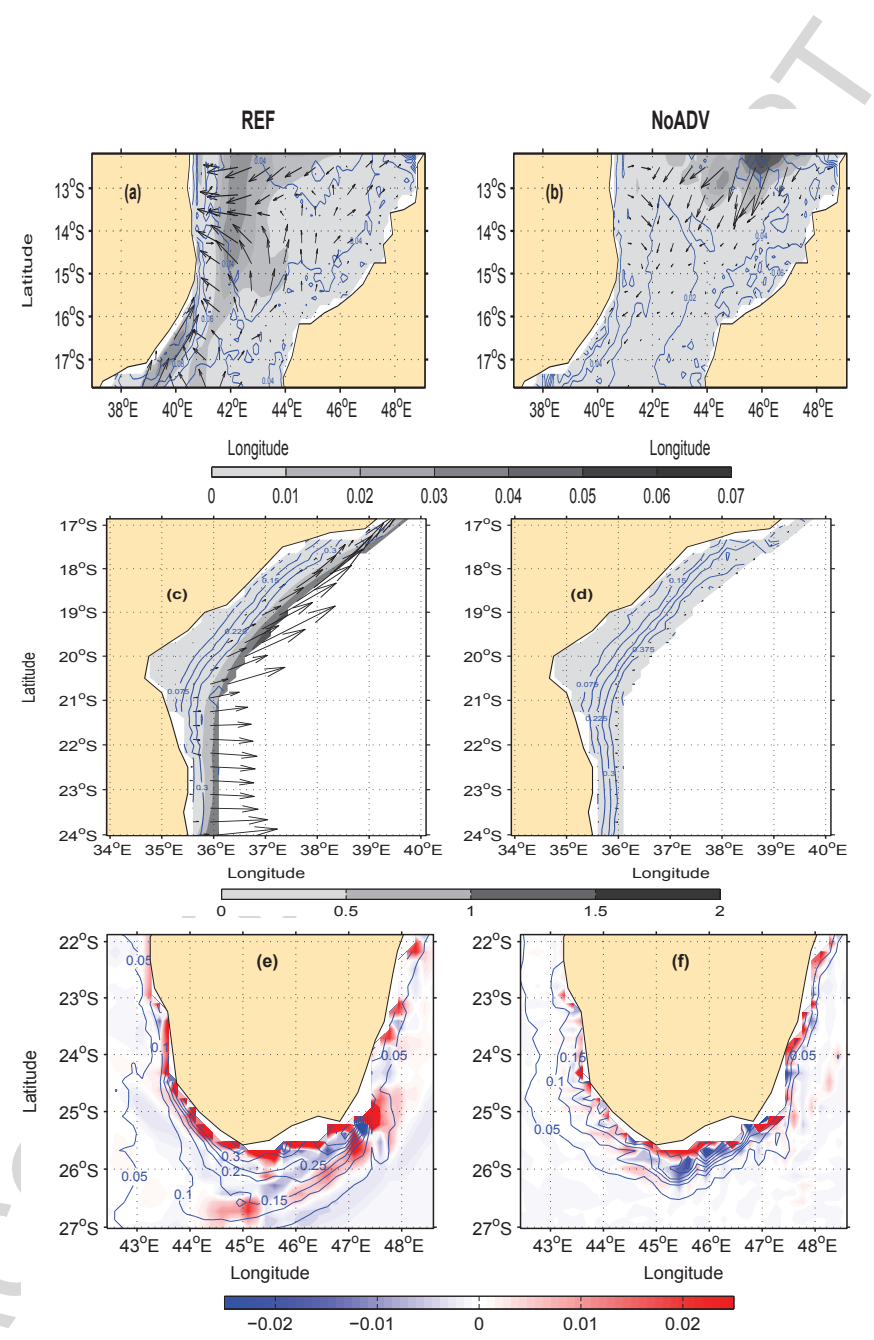

Figure 7: (a,b) New production (contours, $\left[\mathrm{kmol}_{\mathrm{s}} \mathrm{s}^{-1}\right]$ ) overlaid on intensity (colour) and

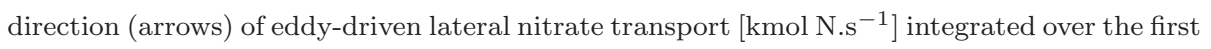
$50 \mathrm{~m}$ in the northern Mozambique Channel. (c,d) The same as (a,b) but for the coastal domain of the central Mozambique Channel integrated from top to bottom. (e,f) New production integrated over the first $50 \mathrm{~m}$ (contours, $\left[\mathrm{kmol}_{\mathrm{s}}{ }^{-1}\right]$ ) overlaid over the mean vertical nitrate transport [kmol N.s $\left.{ }^{-1}\right]$ accross $50 \mathrm{~m}$ depth in the southern Madagascar region. REF (left) and NoADV (right) simulations. Eddy-driven transport are obtained using the Reynolds decomposition method. 

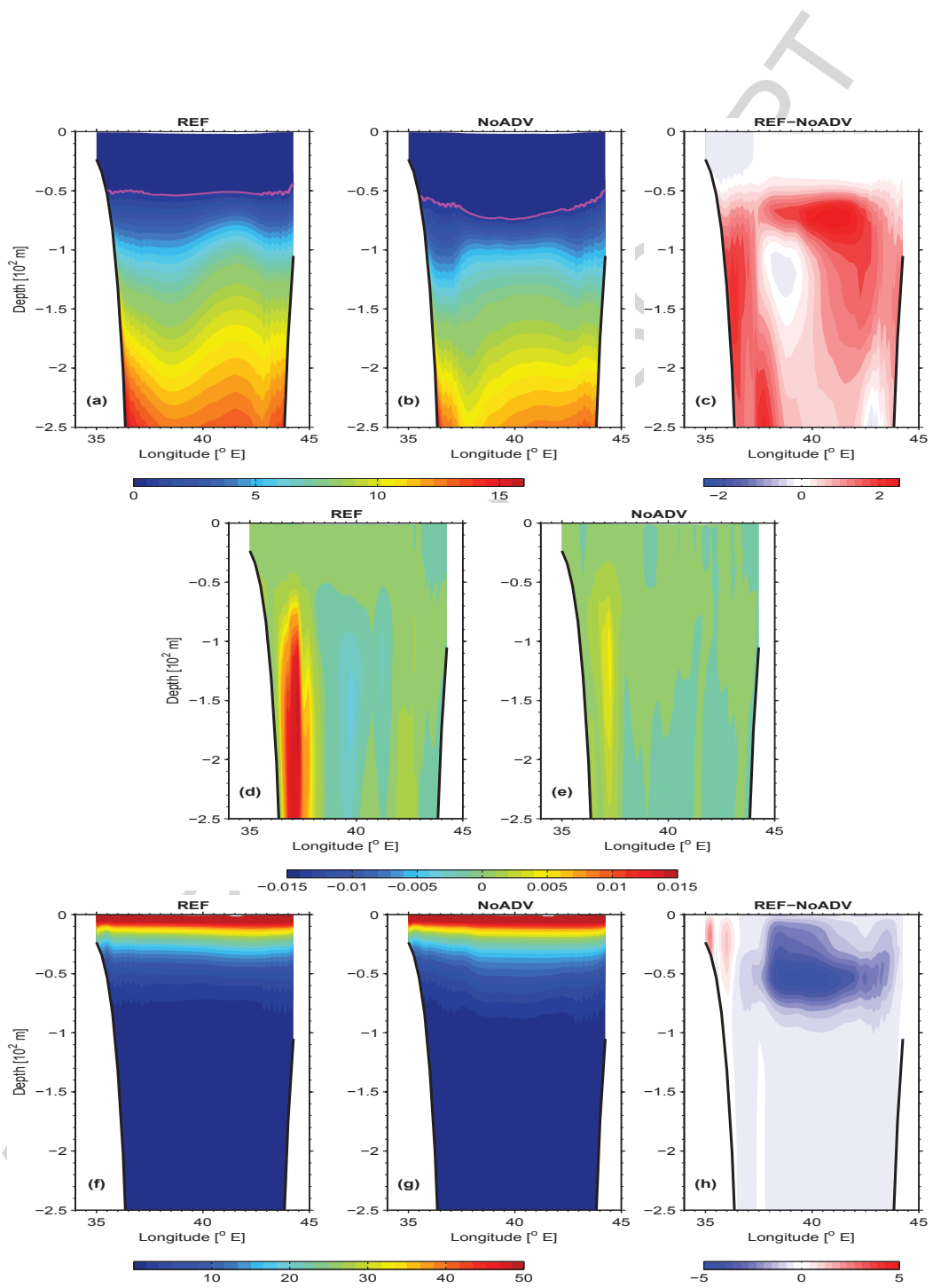

Figure 8: Vertical structure of: (a-c) nitrate concentration $\left[\mu \mathrm{mol} \mathrm{N} . \mathrm{l}^{-1}\right],(\mathrm{d}, \mathrm{e})$ eddy-driven nitrate fluxes $\left[\mathrm{kmol} \mathrm{N.s}{ }^{-1}\right]$ and (f-h) photosynthetic available radiation [W.m ${ }^{-2}$ ], along $20^{\circ} \mathrm{S}$ (section location shown in Fig 5-c). D REF simulation (a,d,f), NoADV simulation (b,e,g) and $R E F-N o A D V$ anomalies (c,h). Eddy-driven transport are obtained using the Reynolds decomposition method. 